(110) 



\title{
Graphisch gestützte Datenanalyse
}

\author{
Von \\ Dr. Rainer Schnell
}

R. Oldenbourg Verlag München Wien 
Anschrift des Verfassers:

Dr. Rainer Schnell

Universität Mannheim

Lehrstuhl für Soziologie

und Wissenschaftslehre

Gebäude A5, 434

68131 Mannheim

Die Deutsche Bibliothek - CIP-Einheitsaufnahme

Schnell, Rainer:

Graphisch gestützte Datenanalyse / von Rainer Schnell. München ; Wien : Oldenbourg, 1994

ISBN 3-486-23118-9

(O) 1994 R. Oldenbourg Verlag GmbH, München

Das Werk einschlieBlich aller Abbildungen ist uheberrechtlich geschützt. Jede Verwertung außerhalb der Grenzen des Utheberrechtsgesetzes ist ohne Zustimmung des Verlages unzulässig und strafbar. Das gilt insbesondere für Vervielfältigungen, Übersetzungen, Mikroverfilmungen und die Einspeicherung und Bearbeitung in elektronischen Systemen.

Gesamtherstellung: R. Oldenbourg Graphische Betriebe GmbH, München

ISBN 3-486-23118-9 